\title{
El Archivo de A. J. Cavanilles en el Real Jardín Botánico
}

\author{
María Pilar de SAN Pío AladréN \\ Paloma Collar del Castillo
}

\section{Antecedentes biográficos}

Antonio José Cavanilles (Valencia 1745-Madrid 1804), probablemente el mejor botánico español de todas las épocas, ha sido objeto de estudio por diversos biógrafos ${ }^{1}$. No se pretende en este artículo mejorar las biografías anteriores, ni hacer una glosa detallada de su vida, sino hacer algunas consideraciones y destacar los aspectos que ayuden a comprender la constitución y organización de su archivo personal, incorporado a los fondos del Real Jardín Botánico en noviembre de 1992.

Por lo que a su formación académica se refiere, llama poderosamente la atención el hecho de que Cavanilles no fuera instruido en la ciencia Botánica en su juventud. La enseñanza institucional que recibió, al menos la que está documentada, fue como hombre de Letras. Sobre ella él mismo llegó, en su madurez, a construir el científico ilustrado, que será incluso introductor de la nueva Ciencia y de las ideas renovadoras en la España de fines del siglo XVIII.

\footnotetext{
${ }^{1}$ Las biografías consultadas son: LAGASCA, M. (1804), Noticia Literaria de la Vida de Don Antonio Josef Cavanilles, texto mecanografiado en la Biblioteca del Real Jardín Botánico de Madrid; Colmeiro, M. (1858), La Botánica y los botánicos de la Península Hispano-lusitana, Madrid, p. 173-175; Pizcueta, J. (1930), Elogio Histórico de Don Antonio José Cavanilles, Madrid, $2^{a}$ ed.; Alvarez LóPEZ, E. (1946), "Ensayo biográfico-crítico», Anales del Jardín Botánico de Madrid 6(1): 1-64; CASAS TORRES, J.M. ed. (1958), «Nota a la presente edición», en CAVANILLES, A.J. Observaciones sobre la historia, geografía, población y frutos del Reyno de Valencia. I vol. $2^{\text {a }}$ ed. Zaragoza, p. VII-XIII; y JAUREGUIZAR, Marqués de (1971), Relación de los poseedores del Castro y Palacio de Prioranza del Bierzo y alguno de sus allegados y descendencia de ellos, Madrid, p. 276-278.
} 
Cursó sus primeros estudios de Humanidades en el Colegio de los Jesuitas de Valencia, posteriormente los de Filosofía en la Universidad de esa misma ciudad $^{2}$, y más tarde, en 1765 , se doctoró en Teología por la Universidad de Gandía ${ }^{3}$. Simultaneó éstos con cierta dedicación a las Matemáticas y la Física, materias que le atraían especialmente.

Se conoce su primera ocupación en la enseñanza de la Filosofía y de las Matemáticas entre 1767 y 1770, así como sus intentos infructuosos por conseguir alguna cátedra. En 1770 entró a trabajar como preceptor del hijo del Oidor de la Real Audiencia de Valencia, Teodomiro Caro de Briones. Cuando éste fue designado Regente en Oviedo, se trasladó con él a dicha ciudad, donde se ordenaría sacerdote en 1772. Más tarde, al recibir Caro el nombramiento de Ministro del Real Consejo de Indias, Cavanilles pasó a Madrid acompañando a esta familia. Gracias a estos viajes, pudo mejorar sus conocimientos geográficos y entablar numerosas relaciones con diversos intelectuales del momento.

A la muerte de Caro, el Obispo de Murcia le contrató como profesor de Lógica en la Cátedra de Filosofía del Colegio de San Fulgencio. Debido a la gran calidad y modernidad de sus clases, adquirió un gran renombre que le valió el ser requerido como preceptor de los hijos del Duque del Infantado, Pedro y Manuel de Toledo; lo que le trajo de nuevo a Madrid en 1776. Como se verá a continuación, este empleo habría de determinar, de forma insospechada, su inesperada dedicación a la Botánica.

En efecto, en junio del año siguiente Cavanilles se trasladó en compañía del Duque y su familia a París, ciudad que experimentaba un auge importantísimo en todas las ramas de las ciencias y lugar ideal para que Cavanilles pudiera tener encuentros trascendentales con destacadas personalidades de la época. Allí se multiplicaban los gabinetes de Historia Natural, tanto de protección Real como particulares, y se mostraban nuevos descubrimientos y técnicas de laboratorio con verdadero carácter científico. Acompañado de sus pupilos, Cavanilles asistió a la Universidad, entrando en contacto con los naturalistas ilustrados más relevantes del momento. Así habría de adquirir su primera formación en Ciencias Naturales.

La predilección por la Botánica se desarrolló a partir de 1780, gracias, fundamentalmente, a su relación con el abate Chaligny y los botánicos Antoine Laurent Jussieu, André Thouin, el Caballero de Lamarck, René Desfontaines, y otros. Bajo estas influencias descubrió su verdadera vocación y.empezó una brillante carrera botánica que pudo llevar a cabo en gran parte con el patrocinio del Duque, quien le enviaría a diversos viajes por Europa, permitiéndole ampliar sus herbarios y mejorar sus conocimientos sobre las plantas.

\footnotetext{
${ }^{2}$ Véase el título correspondiente en el Archivo del Real Jardín Botánico (en adelante ARJB), XIII, 1, 1, 3.

3 ARJB, XIII, 1, $1,4$.
} 
El primer nombramiento que Cavanilles recibió, ya en calidad de botánico, está fechado el 16 de diciembre de 1784, cuando José Pérez Caballero, intendente del Real Jardín Botánico madrileño, le nombró Correspondiente en París de dicha Institución ${ }^{4}$.

Pronto comenzaría la publicación de su primera gran obra Monadelphiae classis dissertationes decem, editando en París en 1785 la primera parte bajo el título de Dissertatio botanica de Sida. Las siete partes siguientes serían publicadas en la misma ciudad, y las dos restantes aparecerían en Madrid en 1790. Su discípulo Mariano de Lagasca destaca que Cavanilles añadió hasta 15 géneros nuevos a esta Clase, agregando algunos que Linneo había incluido en otras Clases, y que el establecimiento de nuevos criterios para fijar los géneros de la Clase produjo las críticas de algunos botánicos.

Al mismo tiempo, en cumplimiento de su misión como preceptor y profesor de Filosofía, elaboró para sus discípulos un texto para el estudio de la Lógica, fechado en 1785, cuyo original forma parte de su archivo.

Su forma de ser, honesta y valiente, le llevó a defender sus ideas y conocimientos frente a los que pensaban de diferente manera no sólo en la disciplina Botánica. Prueba de ello, es la famosa controversia que mantuvo con Masson de Morvilliers por el artículo que éste escribió sobre España en 1782 en la Nouvelle Encyclopédie, al que respondió en 1784 con sus Observations de M.L'Abbé Cavanilles sur l'article «Espagne» de la nouvelle Encyclopédie ${ }^{5}$.

En el campo de la Botánica son conocidas las polémicas que entabló primero con Friedrich Casimir Medikus y con Charles B. de L'Héritier ${ }^{6}$, y más tarde con los españoles Casimiro Gómez Ortega e Hipólito Ruiz, polémicas que recogería en 1796 en la Colección de papeles sobre controversias botánicas de D.Antonio Joseph Cavanilles, con algunas notas del mismo a los escritos de sus antagonistas ${ }^{7}$.

Después de su regreso a Madrid en 1789, publicó las dos últimas partes de las disertaciones de la Monadelphiae..., y acometió el estudio de algunas de las plantas recolectadas por la Expedición de Nueva España de Martín de Sessé, enviadas por el profesor de Botánica Vicente Cervantes desde Méjico. Entre ellas cabe destacar su bien conocido estudio de la especie Dahlia pinnata Cav., dedicada al discípulo de Linneo Andreas Dahl. Fue éste publicado en.1791 en el primer volumen de su segunda gran obra, los Icones et descriptiones plantarum, quae aut sponte in Hispania crescunt, aut in hortis hospitantur, en Madrid, en la Imprenta Real. Los cinco volúmenes restantes aparecerían entre

\footnotetext{
${ }^{4}$ El nombramiento está en ARJB, XIII, 1, 2, 1.

5 Tres ejemplares de esta publicación se encuentran entre los papeles del «Archivo Cavanilles», ahora ARJB, XIII, 9, 4, 1-3.

${ }^{6}$ L'Héritier había trabajado en el herbario de la flora de Perú de Dombey así como en Kew en compañía de Redouté. Sobre la polémica con él ver Observations de M. l'Abbé Cavanilles, de l'Académie de Sciences d'Upsal, sur le cinquième fascicule de M. l'Héritier. Paris, 1789.

7 ARJB, XIII, 9, 5, 1.
} 
1793 y 1801 . En ella describió con gran exactitud hasta 712 plantas, recolectadas en América y en la Península, incluyendo 600 dibujos. Figuran 59 géneros nuevos, y muchas especies nuevas de géneros conocidos. Su trabajo no se limitó a las meras descripciones, está lleno de observaciones sobre Historia Natural, Agricultura y Geografía Humana.

En 1791, recibió la comisión, por Real Orden, de publicar la flora del país; trabajo que no llegó a realizar en su totalidad. Sin embargo, sí dejó un buen ejemplo en sus Observaciones sobre la Historia Natural, Geografía, Agricultura, Población y Frutos del Reino de Valencia (1795-1797). En ellas Cavanilles se reveló no sólo como gran botánico, sino también como brillante escritor, geógrafo y dibujante; por lo que se puede considerar este trabajo modelo en su género. Fruto también de esta comisión sería el estudio sobre el cultivo del arroz, publicado en las Memorias de la Academia de Medicina de Madrid, en 1797, tras ser nombrado miembro honorario de la misma.

En octubre de 1799, el Real Decreto que creaba los Anales de Historia Natural, primera publicación española dedicada exclusivamente a temas de Ciencias Naturales, le nombraba redactor, tarea que compartiría con otros tres grandes científicos: Christiano Herrgen, Louis Proust y Domingo Fernández. En los Anales llegó el botánico a publicar hasta 48 artículos, dando difusión a numerosas descripciones de géneros y especies nuevas y exóticas.

Por fin, en junio de 1801, recibió el nombramiento de Director del Real Jardín Botánico y de la Cátedra de Botánica de la misma Institución, cargos que no abandonaría hasta su muerte en 1804.

En el período de su dirección, emprendió una profunda reorganización del Centro. Estableció una escuela práctica para la enseñanza de la Botánica, y mejoró notablemente las instalaciones con las obras de la estufa para cultivo de plantas exóticas y el estanque. Según Lagasca, Cavanilles aumentó el número de plantas vivas hasta $4.500^{8}$, y formó y arregló el Herbario del Centro, reuniendo hasta 12.000 pliegos; enriquecido con las plantas recogidas por Luis Née, en España y alrededor del mundo, y con su propio herbario, llegando a hacerlo "respetable», según palabras que Cavanilles escribió en una carta a José Celestino Mutis.

Igualmente potenció la política de culminar las investigaciones botánicas mediante su publicación con fondos extraordinarios que le concedían, y consiguió que el resto de los jardines botánicos que existían en España dependiesen de éste. De esta forma llegó a ser, de algún modo, gestor de ellos, decidiendo sobre sus publicaciones y obligándoles a notificar la relación de actividades que realizaban. ${ }^{9}$

\footnotetext{
8 LAGASCA (1804), p. 39.

9 Garilleti, R. y Pelayo, F. (1991), «Las actividades botánicas del naturalista valenciano A.J. Cavanilles», en Hortus Regius Matritensis, Madrid, XI-XXXI, p. XXV.
} 
Corresponde a su etapa de Director la publicación en 1802 de la Descripción de las plantas que.... demostró en las lecciones públicas del año 1801 y 1802, precedida de los principios elementales de la Botánica, obra que, en palabras de Lagasca, «enseña la Filosofía de la Ciencia, en que pesa con conocimiento y crítica imparcial los varios pareceres de los autores, y que presenta con brevedad y concisión los fundamentos que tiene para no seguirlos algunas veces» ${ }^{10}$.

Desgraciadamente, la muerte no le permitió ver publicado el Hortus Regius Matritensis ${ }^{11}$, cuyo manuscrito y dibujos se conservan en el archivo del Real Jardín Botánico. Sin embargo, el proceso de publicación estaba ya empezado en vida del abate ${ }^{12} \mathrm{y}$, como prueba de ello existen 78 estampas grabadas y 45 planchas de cobre en la Calcografía Nacional, realizadas por un equipo de grabadores dirigidos por T. López Enguidanos.

\section{Fuentes documentales sobre Cavanilles en el archivo del Jardín Botánico}

Este resumen de su biografía pone de manifiesto la celebridad y el prestigio que tuvo Cavanilles ya en su tiempo, e induce a pensar en el interés que su archivo personal puede tener para muchos campos de la Ciencia.

Los temas de estudio que pueden derivarse de la lectura e investigación del «Archivo Cavanilles» son muy abundantes: desde conocer más fielmente la biografía y descubrir aspectos desconocidos de la personalidad de Cavanilles hasta ampliar el entendimiento de la propia historia del Jardín Botánico; desde enriquecer nuestras ideas sobre el Movimiento Ilustrado francés hasta afianzar las que teníamos sobre la llegada y el desarrollo en España del mismo; y desde mejorar nuestro conocimiento de ciertas cuestiones relativas a la Historia de la Ciencia hasta ayudarnos a comprender en profundidad una importante etapa de la historia de la Botánica española. En efecto, el archivo refleja la mayor parte de sus relaciones con los botánicos más notables del momento, pero en él también es posible estudiar otras disciplinas como Educación, Pedagogía, Geología, Geografía Humana y otras más. Igualmente, muestra la manera que tuvo de organizar sus estudios y su excelente y sistemático método de trabajo.

Antes de la incorporación de los papeles de Cavanilles al archivo del Real Jardín Botánico, tenía éste un número poco importante de documentos del ilustre botánico, que formaban parte de la documentación histórica de la Institución —o División I-, fechados básicamente entre 1801 y 1804. Entre ellos se reconocen tres grupos: el primero está compuesto por aproximadamente ciento

10 Lagasca (1804), p. 21.

11 Esta obra fue publicada por primera vez en 1991.

12 Veáse la Real Orden para la publicación en ARJB, I, 13, 1, 21. 
treinta documentos oficiales - Reales Órdenes y Oficios- que recogen su gestión en el Jardín y dan fiel cuenta de asuntos puntuales, de personal, de obras de mantenimiento y mejoras del Jardín, de publicaciones, etc...; el segundo grupo es más reducido y recoge los documentos sobre las clases de Botánica que se impartían; y el tercero comprende una treintena de cartas en las que unas veces es Cavanilles el remitente, otras el destinatario y otras el tema principal junto a otros asuntos relacionados con el Jardín. En dicha correspondencia los botánicos intercambiaban información referente a los nuevos descubrimientos de plantas que se estaban realizando tanto en España como en América Central y del Sur. Además se encontraba el manuscrito incompleto con las descripciones del Hortus Regius Matritensis ${ }^{13}$, y la Orden Real de 20 de mayo de 1803 por la que se aprobaba que se hiciese la impresión de esta obra en la Imprenta Real.

Entre los materiales gráficos de esa misma División I también se conservaban obras importantes de Cavanilles. Quizá la más notable -aunque sólo fuera por su extensión- serían los tres volúmenes encuadernados en pasta española, que contienen los 296 dibujos botánicos, a tinta, para la Monadelphiae. Al dorso de la mayoría de ellos figura la firma o rúbrica del autor, el lugar donde los dibujó - Hôtel del Infantado, rue St. Florentin, place de Louis XVy la fecha de cada lámina; la primera realizada el 2 de febrero de 1786 y la última el 24 de agosto de 1789. La ordenación de los dibujos dentro de los volúmenes parece atenerse a las fechas, aunque sin demasiado rigor. También es de reseñar que en la contra-cubierta de cada volumen aparece, en el ángulo superior izquierdo, una etiqueta que indica su procedencia y dice: «Casa del S. Corazón/ Chamartín/ Bibl. de Estudios», hecho que demuestra que esta obra formó parte de otra biblioteca. También queda ésto patente al abrir cada tomo y ver las notas manuscritas que aparecen en la portada:

"Obsequio/ de las religiosas del Sagrado Corazón/ a la señora/ D. ${ }^{\text {a Antonia }}$ Cavanilles/ Condesa viuda de Cerragería/ sobrina-nieta del autor./ 1er Viernes, 6 de Febrero de 1920"

y a continuación:

«La donó al Rl. Jardín Botánico de esta/ Corte como homenaje a la memoria/ del sabio Sacerdote Dn. Antonio José Cavanilles,/ su autor/ Antonia Cavanilles y Federici/ Cda. Vda. de Cerrageria/ Febrero de 1920».

Dentro de esta misma División I se encontraba también la colección de dibujos originales para el Hortus Regius Matritensis, constituida por 100 dibu-

\footnotetext{
13 Este manuscrito se encuentra en ARJB, I, 13, 5 y una copia incompleta de las descripciones del Hortus de varias letras está en ARJB, I, 14, 1, 3 .
} 


\section{EL ARCHIVO DE A.J. CAVANILLES EN EL REAL JARDIN BOTANICO}

jos botánicos a tinta, encuadernados en un tomo, con cubiertas y puntas de papel de guardas y lomo de piel. Fueron éstos realizados en su mayoría por el dibujante del Real Jardín Botánico José Guío con la colaboración de otro artista, Antonio Delgado Meneses, y ambos bajo la dirección de Cavanilles, quien también hizo algún dibujo. En general son representaciones de plantas nuevas que nacieron de semillas traídas por las expediciones americanas, sembradas en las estufas del Jardín, donde se cultivaban y estudiaban para ser clasificadas y descritas.

Por último, el Real Jardín Botánico también poseía una colección de grabados de época de la gran obra de Cavanilles sobre el Reino de Valencia y otra más, de los Icones.

\section{La incorporación del "Archivo Cavanilles» y su acondicionamiento}

Sin embargo, hasta fines de 1992, la mayor parte de los documentos de Cavanilles se encontraba en su archivo personal y éste había quedado en manos de sus descendientes, quienes lo iban custodiando celosamente, pasando de generación en generación.

El «Archivo Cavanilles» entró en el Real Jardín Botánico gracias a las acertadas gestiones y al tesón del Dr. D. Santiago Castroviejo, y a la buena voluntad y generosidad de la familia propietaria. El hecho es destacable porque supuso la incorporación al archivo de esta institución de un fondo completo de muy alto interés para la misma y de gran calidad científica. Por ello, el Real Jardín Botánico acogió el fondo Cavanilles con especial satisfacción.

El depósito del «Archivo Cavanilles» en el Real Jardín Botánico se realizó de la manera siguiente: el 6 de noviembre de 1992 las hermanas Doña Marta, Doña Concepción y Doña Carmen Valdés Arroyo, así como Don Alfonso Muñoz Valdés, todos ellos herederos directos del ilustre botánico, lo entregaron en la sede central del Consejo Superior de Investigaciones Científicas a su Presidente el Dr. D. José María Mato de la Paz y al Dr. Castroviejo, entonces Director del Real Jardín Botánico. El acto se celebró ante el notario D. José Ignacio Fuentes López quien levantó un Acta de entrega por la que la familia cede por tiempo indefinido el uso de dicho archivo, señalando como únicas condiciones las siguientes:

1. que el Real Jardín Botánico editara un catálogo,

2. que la familia Cavanilles tuviese el derecho a consultar libremente dicho fondo, respetando las condiciones generales que el archivo establece para la buena conservación del mismo,

3. que dicha entidad les enviara una copia de todo lo que se publicase como resultado de las investigaciones en dichos papeles. 
La ordenación que el archivo tenía se debía al General Luis Valdés Cavanilles, que organizó los documentos en 12 grupos temáticos e instaló cada uno en una caja-archivadora, que denominó "carpeta», de lomo de piel con nervios y cubiertas enteladas, proporcionada a la extensión de su contenido. Dentro de ellas reunió los documentos en unas "carpetillas" - hoy carpetas-, hechas también ex profeso e impresas con la imagen de Cavanilles y el nombre del archivo, que rotuló y numeró para dar uniformidad al conjunto. Cada caja correspondía a una serie documental y, dependiendo de la documentación que albergara, llevaba más o menos carpetas. Al integrarse al archivo del Jardín, se respetó esta ordenación y, aunque en el legado venían varias obras impresas, que podían haber pasado a la biblioteca del Ćentro, éste no se dividió y la colección íntegra se incluyó en el esquema general de los fondos del archivo en la Sección de Colecciones Particulares, como División XIII. Actualmente, la signatura que identifica cada documento está compuesta por el número XIII de la división, seguido del número de la caja —o serie-, el de la carpeta correspondiente, y el propio de cada documento.

Se decidió respetar en todo lo posible el orden original, tanto por motivos archivísticos, como por la difusión que pudiera haber tenido el catálogo publicado por el General Valdés en 1946.

El paso siguiente fue proceder a una inspección general de los documentos recibidos, comparándolos con el inventario publicado, para levantar un informe exhaustivo del estado de conservación, acometer las tareas de restauración más urgentes y frenar en lo posible cualquier proceso de deterioro.

Si bien cabe decir que en líneas generales los fondos estaban bien conservados, los dibujos originales del Reino de Valencia ${ }^{14}$ así como el tomo de documentos de José Thomas Cavanilles ${ }^{15}$ tenían daños causados por humedad.

En todo el fondo se realizó un primer acondicionamiento y limpieza, sustituyendo provisionalmente cada carpetilla por otra de papel neutro, con el fin de, una vez terminado todo el proceso de restauración, cambiarlas definitivamente por camisas de papel barrera con reserva alcalina, e instalarlas de modo permanente en cajas-archivadoras de conservación. Una vez signada y foliada, la colección fue microfilmada para facilitar la consulta inmediata a los investigadores, sin perjudicarla con el uso muy continuado. Esta microfilmación se integró en el proyecto general realizado con todos los manuscritos del archivo, microfilmados en el marco de un convenio firmado con la Dirección General de Bellas Artes del Ministerio de Cultura a través del Servicio de Reproducción de Documentos de la Subdirección de Archivos Estatales.

Dado el trabajo extraordinario que suponía para el Jardín Botánico restaurar y catalogar el "Archivo Cavanilles", se decidió elaborar un proyecto

14 ARJB, XIII, 7, 9.

15 ARJB, XIII, 12. 
para llevar a cabo, con financiación externa, todos los procesos exigidos por la nueva adquisición. En la convocatoria de 1994 se solicitó una ayuda para la realización del proyecto «Estudio, Restauración y Catalogación del fondo Cavanilles» en el área de Humanidades y Ciencias Sociales del II Plan Regional de Investigación de la Comunidad de Madrid. La solicitud fue seleccionada y estimada favorablemente por la Consejería de Cultura de la Comunidad, encuadrándola en el área de Patrimonio Histórico de la Dirección General de Patrimonio Cultural, y concediendo dos millones de pesetas para atender a la mayor parte de los gastos.

Como se ha mencionado más arriba, los primeros pasos en conservación preventiva ya han sido dados. La restauración que se pretende acometer en el desarrollo del citado proyecto implicará procesos de limpieza de documentos, y tratamientos que aseguren la perdurabilidad de los mismos.

El proceso de catalogación está en su inicio, y le queda aún un largo recorrido. Los instrumentos de descripción que existen actualmente no son todavía los idóneos. Se pretende crear un catálogo muy detallado, para lo que se va a aplicar la siguiente metodología: tras la lectura completa de cada documento, se redactará un resumen o extracto absolutamente riguroso del contenido, y se hará el vaciado de nombres de personas, lugares e instituciones que aparezcan en la totalidad del documento. Por supuesto, se dará la fecha, lengua en que está escrito, descripción física, notas, etc... , así como las materias de que tratan. A continuación, se informatizarán las fichas elaboradas creando con ellas una base de datos, que servirá tanto para gestionar el fondo, revisarlo, y modificar su catalogación si procede, como para hacer las búsquedas que requieran los investigadores. Todo este proceso culminará con la edición de un catálogo impreso, para mejor difundir los trabajos del insigne botánico, y así unir el deseo de la familia y el del propio Real Jardín Botánico.

En la actualidad la única fuente de información sobre el "Archivo Cavanilles» es el catálogo de 1946, publicado con motivo de la exposición conmemorativa del II Centenario de su nacimiento con el título Archivo del Ilustre Botánico D. Antonio José Cavanilles del que son poseedores los Sres. hermanos Valdés Cavanilles y sus primos, los Sres. hermanos Vigil Cavanilles. En él aparece descrito el contenido de las carpetas de las doce cajas de que consta el fondo, pero se ha advertido que figuraban varias confusiones en fechas y nombres, e imprecisiones en cuanto al número real de documentos. Para subsanar estos errores, el presente artículo presenta una primera síntesis revisada y comentada de esta documentación, anticipo de la catalogación que se va a efectuar y colaboración a la celebración de este doscientos cincuenta aniversario.

A simple vista, se observa que los documentos son en general de muy fácil lectura: por una parte, muchos corresponden a la clara letra del abate y, por otra, son en su mayoría documentos ya elaborados y no borradores, ni copias. En las numerosas cartas que Cavanilles recibía, a menudo escribía en una 
esquina del papel una nota con la fecha en que contestaba e incluso los pequeños gastos de envío; datos que facilitan la tarea de cruzar su correspondencia y dan muestra de su mente clara y ordenada.

En cuanto a los tipos documentales representados, se advierte un número aproximado de 1.300 cartas que Cavanilles recibió por los más diversos motivos: unas de ilustres botánicos de toda Europa, otras relacionadas con la publicación de sus obras, muchas de ellas desde París y escritas en francés (idioma que Cavanilles debía conocer perfectamente), otras de sus familiares más allegados - de las que se conservan también las que él envió a su sobrino Pepe (José Cavanilles) - , y un último gran grupo con la correspondencia que fue recibiendo para la redacción de las Observaciones sobre la Historia Natural del Reino de Valencia.

Además de la correspondencia se debe subrayar el importante número de dibujos que incluía el archivo. Todos ellos vinieron encuadernados: tanto los 600 dibujos de los Icones - representaciones de plantas que incluían a veces también sus anatomías-, como los 51 originales para la obra del Reino de Valencia. Estos últimos, de temática muy diferente a los anteriores, son fundamentalmente paisajes valencianos, pero también tocan temas arqueológicos y otros sobre obras hidráulicas. Todos están realizados con la misma técnica. Llama la atención el hecho de que Cavanilles nunca usara colores en sus dibujos fuera de la gama de los grises, como los emplearon muchos dibujantes botánicos de la época. Sin duda, sus dibujos fueron creados expresamente para que, posteriormente, los grabadores realizaran la cuidadosa tarea de abrir las planchas —o láminas- de cobre. Emplearon éstos la técnica llamada a la talla dulce y de las láminas así grabadas se estamparon las imágenes para incorporarlas a las obras impresas. Entre los grabadores que Cavanilles empleó para realizar sus trabajos se distinguen dos grupos diferentes: el primero compuesto por grabadores franceses, cuyo representante más sobresaliente es F.N. Sellier, quien grabó un número importante de las obras publicadas en París, y el segundo grupo relacionado con los grabadores de la Real Calcografía, siendo Vicente López Enguidanos el representante más destacado con quien colaboraron su hermano Tomás, M. Gamborino, J. Fonseca y A. Blanco.

\section{Descripción del "Archivo Cavanilles»}

La relación de los contenidos de las cajas —o series- de documentos, llamadas carpetas en el catálogo de 1946, es la siguiente:

1. La primera caja está constituida por la serie nombrada BIOGRAFÍA. Su documentación refleja la trayectoria de la formación de Cavanilles, de su brillante historial académico y del notable reconocimiento internacional. 


\section{EL ARCHIVO DE A.J. CAVANILLES EN EL REAL JARDIN BOTANICO}

Dentro de ella se distinguen tres subseries:

a) Títulos y Honores: compuesta por 24 carpetas con nombramientos de sociedades y academias europeas estudiosas de Medicina e Historia Natural, acompañados en muchos casos del oficio de remisión, y los títulos de sus estudios universitarios. Cabe destacar los Títulos de la Sociedad Linneana de Londres y de la Academia de Ciencias de San Petersburgo. Cinco carpetas contienen otros documentos puntuales sobre su vida, escritos por terceras personas.

b) Testamentaria: comprende 5 carpetas con documentos sobre la testamentaría del abate y sobre la compra de su biblioteca de Historia Natural, después de su muerte, por parte del Real Jardín Botáni$\mathrm{co}^{16}$, y una que explica los pasos de Cavanilles para poder conseguir la Abadía de Ampurias y poder ser llamado así abate.

c) Administración: es la última subserie: Tiene sólo 2 carpetas con recibos de los gastos de las cocheras y coches que poseía en Madrid, y dos letras de cambio.

2. La segunda serie se titula TRABAJOS CIENTÍFICOS Y LITERARIOS. Está compuesta por 21 carpetas.

En ellas se encuentran diversos tipos de documentos: desde el manuscrito original de las «Ligeras observaciones sobre los insultos que Mr. Masson de Morvilliers...», a otro copiado titulado "Reflexiones para mejorar la enseñanza de las Ciencias Naturales"; desde oficios del Príncipe de la Paz - con el pasaporte emitido a Cavanilles por Godoy en Aranjuez a 24 de marzo de 1793 para recorrer la geografía de España con el fin de poder herborizar-, hasta el reglamento del Real Gabinete de Historia Natural o un certificado del Instituto Nacional de París acerca del artículo de Cavanilles «Polvos contra la Rabia»; y desde estudios botánicos o de mineralogía (por Herrgen), a oficios y minutas, y otros escritos relacionados con el Jardín Botánico, la entrega de plantas, la publicación de los anales, incluyendo así mismo discursos y cartas a su familia.

Cuatro carpetas, con fecha de 1820, corresponden a su sobrino José Cavanilles y también versan sobre Botánica.

3. La tercera serie se titula CORRESPONDENCIA CIENTÍFICA. Contiene casi 200 cartas de 55 remitentes, cuya relación sigue. Así mismo se indica el número de cartas de cada uno y el año o años de su envío, sin añadir datos de los documentos que en muchos casos acompañan y omitiendo el destinatario siempre que se trate de Cavanilles. Su temática es fundamentalmente botáni-

16 En ARJB, I, 22, se encuentran documentos interesantes sobre la adquisición de su biblioteca. 
ca, aunque también escriben anunciando el envío o intercambio de libros y folletos y sus últimas publicaciones.

1. 1801-1802.-Tres cartas de Juan Aguiar desde París.

2. 1784-1804. - Quince cartas del naturalista Pierre Marie Auguste Broussonet.

3. 1798-1803.-Tres cartas del botánico portugués Félix Avellar Brotero.

4. 1803-1804.-Dos cartas de D'Audebard de Férussac, ex-capitán de Artillería.

5. 1796-1798. - Cuatro cartas de F.C. Achard, Director de la clase de Física de la Real Academia Prusiana de Ciencias.

6. 1785-1786.-Nueve cartas de Ignacio de Asso desde Amsterdam.

7. 1804.-Una carta del General Beurnonville, embajador de Francia en España.

8. 1804.-Una carta de Burin desde Ginebra.

9. 1803.-Una carta de Giovanni Battista Balbis, director del Jardín Botánico de Turín.

10. 1797.-Una carta de Giuseppe Antonio Bonato desde Padua.

11. 1785-1789.-Nueve cartas de Sir Joseph Banks desde Londres.

12. 1803. - Dos cartas del Duque de San Isidro Caracciolo desde Madrid.

13. 1802.-Dos cartas de José María Caval desde París.

14. S. A. (1802).--Una carta de [Georges] Cuvier, Secretario de la Clase de Ciencias Matemáticas y Físicas del Instituto Nacional de París.

15. 1801.- -Una carta del librero Cotta.

16. 1803-1804. - Ocho cartas de Thomas Duverne.

17. 1802-1803.-Tres cartas de Clelia Durezzo Grimaldi.

18. 1801-1804.-Tres cartas de Auguste Destreux desde Nîmes.

19. 1798-1800.-Dos cartas del botánico René Desfontaines.

20. 1785-1789.-Diez cartas del Barón de Dillon desde Londres.

21. 1785-1788.-Tres cartas de Joseph Dombey.

22. 1803.-Una carta de Gaspar Escher desde Zurich.

23. 1801-1803.-Cuatro cartas del Antoine Gouan, Profesor de Botánica.

24. 1801.-Una carta del Doctor José Garriga [y Buach] desde Montpellier.

25. 1798. - Tres cartas de Ferdinand Pierre Guillermardet, Embajador de Francia en España.

26. 1796.-Una carta-oficio de [Gregorio] García Fernández de la Real Academia de Medicina de Madrid.

27. 1792.- - Una carta del naturalista y geólogo Carlos de Gimbernat a [Casimiro Gómez] Ortega desde Londres.

28. 1793.- -Una carta de Joan Hedwig desde Leipzig (latín).

29. 1798-1801.-Del Conde [Johann Centurius] Hofmannsegg desde Lisboa.

30. 1803. - Una carta de [Friedrich Alexander] Humboldt y de Aimé [Goujaud] Bonpland desde Méjico. 


\section{EL ARCHIVO DE A.J. CAVANILLES EN EL REAL JARDIN BOTANICO}

31. 1787-1804.-Trece cartas del botánico austríaco [Nikolas] Joseph Jacquin desde Viena.

32. 1785-1800.-Veinticuatro cartas del botánico [Antoine Laurent] de Jussieu.

33. 1802.-Dos cartas de [Johann Simon] Kerner de Stuttgart.

34. 1803-1804.-Tres cartas de Josue Leon desde Bayona.

35. 1803.-Dos cartas del botánico [Jacques Julien Houttou de] Labillardière desde el Instituto Nacional de París.

36. 1803.- -Una carta de Sebastián José López Ruiz, de Santafé.

37. 1802. - Una carta de [Bernard Germain Étienne de La Ville, Conde de] Lacépède, del Instituto Nacional de Ciencias y Artes de Francia.

38. 1801.-Una carta de Rafael Mariano de León, de Córdoba.

39. 1801.- Tres cartas de André Pierre Ledru.

40. 1798-1799.-Dos cartas del botánico Johann Heinrich Friedrich Link, sucesor de Willdenow en el Jardín Botánico de Berlín, desde Lisboa.

41. 1797.-Una carta del naturalista [Jean Baptiste] Lamarck.

42. 1803.-Una carta de [Charles François Brisseau de] Mirbel.

43. 1802. - Una carta del botánico [André] Michaux, del Instituto de Francia.

44. 1798-1802.-Cuatro cartas de Joseph Gottfried Mikan, Catedrático de Botánica en Praga (latín).

45. 1795-1803.-Seis cartas de José C. Mutis y de Sinforoso Mutis desde Santafé de Bogotá.

46. 1803. - Una carta de [Noël Joseph] Necker de Ginebra.

47. 1797.- - Una carta de Luis Née.

48. 1785-1810.-Once cartas de su antecesor en la dirección del Jardín Botánico, Casimiro [Gómez] Ortega.

49. 1803. - Una carta de Didacus Pascal (V.a. Diego Baldassare) desde Parma (latín).

50. 1801-1802.-Tres cartas de Patrin, miembro asociado del Instituto Nacional de Ciencias y Artes.

51. 1795-1797.-Dieciocho cartas de don Luis, Príncipe de Parma, desde Aranjuez y San Lorenzo.

52. 1795.--Una carta de [Peter Simón] Pallás, desde San Petersburgo.

53. 1789.- - Una carta de José Pérez Caballero.

54. 1787.-Una carta del botánico José Pavón desde Huanauco.

55. 1785.-Cinco cartas de Antonio Paláu.

4. La caja siguiente se llama también CORRESPONDENCIA CIENTÍFICA, y es la segunda parte de la anterior y de temática similar. Incluye un número superior a 200 cartas a partir de la letra $R$ aunque la ordenación alfabética no es del todo exacta. 
1. 1791-1804.-Dos cartas del Doctor J. Redousky, médico-botánico desde Moscú.

2. 1794-1804.-Dos cartas de Filippo Re (italiano).

3. 1798.-Una carta de Louis Marie La Revellière L'Epeux.

4. 1803.- -Una carta de Simón de Rojas Clemente.

5. 1788. - Una carta de Hipólito Ruiz, desde Madrid.

6. 1804.-Una carta de J. Rist.

7. 1792.--Una carta de Joannes Christianus Daniel Schreber (latín).

8. 1789-1803.-Diecinueve cartas de Jacques Edouard Smith de Londres.

9. 1803-1804.--Seis cartas de John Stackhouse.

10. 1807.-Una carta del Abate François Solari.

11. 1803.-Una carta del profesor de Botánica [Curt] Sprengel.

12. 1798-1802.-Seis ; cartas de [Peder] Schousboe, cónsul de Dinamarca en Tánger.

13. 1784-1785.-Diecisiete cartas de Cándido María Trigueros desde Sevilla y Carmona.

14. 1786-1800.-Venticuatro cartas del botánico [Carl Peter] Thunberg de Upsala.

15. 1785-1800.-Doce cartas del Profesor del Museo de Historia Natural de París, André Thouin.

16. 1786-1797.-Veintinueve cartas de Paul Usteri (latín).

17. 1797-1800. - Tres cartas de Martin Vahl, desde Amsterdam y Copenhague.

18. 1798-1804.- -Treinta y siete cartas del botánico Etienne P. Ventenat.

19. 1791.-Una carta de Erico Nyssen Viborg de Copenhague.

20. 1788-1803.-Seis cartas de Carl Ludwig Willdenow, director del Jardín Botánico de Berlín.

21. 1801.-Una carta de [Franz de Paula Adam], Conde de Waldstein, desde Viena.

22. 1784.-Una carta del Abate Ximénez.

23. 1798-1802.-Doce cartas del Dr. Attilio Zuccagni, Prefecto del Jardín Botánico de Florencia (italiano).

24. 1798-1802.- Treinta cartas de Francisco Antonio Zea.

5. La quinta serie está dividida en dos subseries:

a) CORRESPONDENCIA LITERARIA con 14 carpetas de otros tantos autores y un total de 108 cartas, $y$

b) CORRESPONDENCIA PARTICULAR con 7 carpetas de igual número de remitentes y 19 cartas en total. Las dos últimas, dirigidas por el duque del Infantado a José María Cavanilles Centí, acompañaban el envío del manuscrito encabezado "Compendio de Lógica» que el botánico utilizó para la enseñanza de sus pupilos. El contenido general de esta serie es: 
1. 1801-1802.-Dos cartas de Carlos Andrés desde Valencia.

2. 1784-1803.-Cuarenta y tres cartas del Abate Juan Andrés desde Mantua, Roma y Parma.

3. 1796-1797.-Cinco cartas de Blasco desde Valencia.

4. S. A..-Dos cartas de la Duquesa de Beaufort.

5. 1785.-Una carta del Abate Andrés Celle, profesor de los hijos del Conde de Fernán Núñez desde Lisboa.

6. 1788-1792.- Trece cartas del Duque del Infantado, una de ellas dirigida a Sanbaignez.

7. 1797.-_Una carta de Gaspar de Jovellanos.

8. 1777-1785.-Ocho cartas del historiador Juan Bautista Muñoz.

9. 1796-1798.-Cinco cartas del conservador de la Biblioteca Nacional de París Aubin Louis Millin.

10. 1801-1803.- - Tres cartas de Salvador Rizo desde Santafé.

11. S.a.-Doce cartas del Príncipe Charles de Salm-Salm.

12. 1789.- - Siete cartas del Conde de Saldaña, desde Madrid, Amsterdam y San Petersburgo.

13. 1789.- - Tres cartas de Manuel de Toledo y Salm-Salm.

14. 1789-1790.- - Tres cartas de la Duquesa del Infantado (nacida SalmSalm).

15. 1803.-Dos cartas de Matías Bertrán de Valencia.

16. 1785.- Una carta del Duque de Fernán Núñez desde Lisboa.

17. 1783-1803.-Cuatro cartas de Mariano Gay de Valencia.

18. 1784-1786.-Once cartas de Mariano Pinazo, Mayordomo y Secretario del Duque del Infantado.

19. 1793.- Una carta de Víctor Quirós, médico de Morella.

20. 1805.- Una carta del Duque del Infantado a José Cavanilles Centi.

21. 1818.- Una carta del Duque del Infantado a José Cavanilles Centi.

22. Una carta de Luis Principe de Parma.

6. La serie sexta tiene por título BIBLIOGRAFÍA. Está compuesta por 28 carpetas con diferentes tipos documentales. Versa sobre asuntos relacionados con la edición, publicación, distribución y costes de sus obras impresas. Destaca la correspondencia mantenida con un grupo selecto de libreros de París, y los recibos de los pagos hechos a los grabadores y dibujantes de plantas.

1. 1796.-Un recibo de Santiago Agustín, relacionado con los Icones plantarum.

2. 1793-1795.- Seis recibos del director de la Real Calcografía, Nicolás Barsanti, sobre las láminas de las obras de Cavanilles.

3. 1800.-Un oficio de Juan Facundo Caballero, relacionado con los Anales de Historia Natural. 


\section{MARIA PILAR DE SAN PIO ALADREN Y PALOMA COLLAR DEL CASTILLO}

4. 1790-1800.-Siete recibos de los grabadores Miguel Gamborino, Tomás y Vicente López Enguidanos, José Fonseca y Alejandro Blanco, y del dibujante Carlos de Vargas Machuca.

5. 1797.-Un certificado de Andrés Ponce, referente al tomo IV de los Icones plantarum.

6. 1796.-Un recibo de Pedro Julián Pereyra sobre la edición de 400 ejemplares de Colección de papeles sobre controversias botánicas.

7. 1798.-Un recibo de Pedro Julián Pereyra sobre la impresión de 300 ejemplares de las Observaciones sobre el cultivo del arroz.

8. 1790-1797.-Diez y ocho cartas del grabador Sellier.

9. 1792.-Un oficio de Julián López de la Torre Ayllón sobre la financiación de publicaciones.

10. 1801.-Un oficio de la Clase de Ciencias del Instituto Nacional, de París, agradeciendo el envío de tres números de los Anales de Ciencias Naturales.

11. 1792-1801.-Tres relaciones de cuentas de los años 1792 a 1801 de los gastos de edición de sus obras.

12. 1789.-Dos recibos de envíos a Madrid.

13. 1803.-Dos cartas de Diego Crespo de Tejada y de Gordia Bayo y Cía. sobre portes de libros.

14. 1798.-Tres cartas del librero de la Corte, Degen.

15. 1784-1798.-Ocho cartas del editor Didot.

16. 1784-1804. - Nueve cartas de Pascual Escrich de Cádiz.

17. 1796-1816.-Ciento cincuenta y nueve cartas del librero Juan B. Fournier, también a José Cavanilles, a Antonio Cavanilles, a Villanueva y al Marqués de Santa Cruz.

18. 1802.-Una carta del librero Garnery.

19. 1790-1791.-Una carta y recibo de José Gisbert y Domenech sobre la compra de papel.

20. 1790.-Un recibo de Lázaro Gayguer sobre la edición de 300 ejemplares de las Disertaciones IX y X.

21. 1787.-Tres cartas del Marqués de Llano.

22. 1792-1800.-Veintiseis cartas del librero Prevost.

23. 1801-1802.-Dos cartas de los Sres. Reymann y Co.

24. 1801.-Dos cartas del impresor y librero Charles Pougens.

25. 1799.- - Una carta del librero Reymann.

26. 1795.-Una carta del librero Saubaigné al librero Fournier.

27. 1792.-Dos cartas de Francisco Pérez Bayer a B. Fournier.

28. 1802.-Una carta de Mr. Thore, de Dax. 
7. La serie séptima está llamada OBRAS «REYNO DE VALENCIA».

En esta caja además de toda la documentación del "Reyno de Valencia», se incluían los dibujos originales para los Icones plantarum.

Cavanilles fue designado para realizar un estudio completo de la flora del país y, aunque no llegó a abarcar todo el territorio nacional, sí lo llevó a cabo en el Reino de Valencia con gran calidad y profundidad. Los documentos que se conservan de las Observaciones sobre la Historia Natural... del Reino de Valencia son muy valiosos porque explican su modo de trabajar. Afortunadamente, hay materiales de las tres etapas de creación: los primeros borradores realizados in situ, los resultados de su elaboración posterior y el producto final, los libros impresos. La primera etapa del trabajo se refleja en el Diario, conjunto de cuadernillos de papel verjurado, tamaño folio, con un total de 218 hojas entre las dos partes que lo componen -144 y 74 hojas cada una de ellas respectivamente. Los trabajos de campo fueron realizados del 20 de marzo al 3 de octubre de 1792, y del 16 de abril al 17 de agosto de 1793. El documento está ordenado cronológicamente, en función de la programación de sus excursiones. Reseña día a día lo más interesante sobre las plantas silvestres y la formación geológica del terreno, valorando, en ocasiones, la calidad de la tierra para el cultivo. También apunta lo que le llamaba la atención sobre las características de las producciones de cada lugar, los métodos artesanales de transformación de las materias primas, como la pita o el esparto, y sobre los cultivos de todo tipo: arroz, árboles frutales y otros. Termina con unas observaciones detalladas sobre las medidas de longitud que se usaban en el momento: la vara valenciana, la media legua municipal y la milla romana; estas medidas las utilizará en la escala de los dibujos para dar con exactitud las distancias reales entre los lugares.

En las carpetas donde estaba el Diario se ha alterado el orden original de la documentación. Cuando llegó al archivo del Jardín Botánico, el Diario tenía intercalados 379 documentos, procedentes de diversos lugares de la geografía valenciana por los que Cavanilles había pasado y donde había encargado que le dieran noticia de las producciones - tanto agrícolas como manufacturadas-, de los censos de población y otros datos que no hubiera podido recoger. Para conseguir su propósito se apoyó en las autoridades eclesiásticas y en la élite de personajes ilustrados, médicos y otros cargos relevantes de las localidades. Las cifras que consiguió sobre las producciones son muy fiables, no sólo porque el clero cobraba impuestos sobre los cultivos, sino porque eran vecinos y conocían la realidad de lo que pasaba en sus pueblos mucho mejor que la administración central. Encargó los censos de población a los archivos parroquiales que eran, en ese momento, unas fuentes estadísticas perfectas para lo que él requería, aunque también los consultó personalmente. En el prólogo de su obra expone esta metodología de trabajo. 
Sin duda, el propio Cavanilles fue colocando estos papeles entre las hojas del Diario, en el lugar correspondiente, de donde procedía la nueva información, y fue agrandando la extensión original del Diario. Esto perjudicaba su buena conservación y ha sido necesario separar dichos documentos suplementarios, creando con ellos dos nuevas carpetas. Se ha anotado la página del Diario donde se ha hallado cada papel, y se han organizado siguiendo el orden de aparición de cada localidad en la obra impresa, distinto del que tienen en las excursiones que narra el Diario.

Entre los papeles agregados, figuraba así mismo una serie de bocetos realizados por el propio Cavanilles de los lugares que visitó. Tienen un gran encanto y cierta ingenuidad por su sencillez $\mathrm{y}$, aunque son esquemáticos, no olvidan pequeños detalles que les dan calidad humana. Los temas de los dibujos varían: desde los que representan paisajes montañosos o marítimos, hasta los que copian el esquema de la construcción de una acequia para el regadío, o los que recogen detalles arqueológicos, copiando las inscripciones de columnas y lápidas. Están realizados sobre papel verjurado, a lápiz y tinta sepia como el resto del Diario. En algunas ocasiones tienen tamaño superior al folio y en otras formas irregulares.

La segunda fase de la realización de la obra del Reino de Valencia está representada pór dos volúmenes manuscritos en tinta sepia, autógrafos y rubricados por Cavanilles, y un tercero con los dibujos originales. Todos ellos muy terminados y preparados para la imprenta. Son de tamaño folio, papel verjurado y encuadernados con cubiertas de cabra verde, gofradas con orla dorada y guardas serigrafiadas. Contiene el primer volumen 285 hojas, más 8 que recogen el prólogo; el segundo volumen está compuesto por 303 hojas, más 31 que forman los diferentes índices de lugares y plantas. El tercero contiene 52 dibujos en folio y un mapa de grandes dimensiones, preparados para que los grabadores abriesen las planchas de cobre. Veintisiete de estas planchas se encuentran en la Calcografía Nacional ${ }^{17}$.

El dibujo de éstas es de más calidad que el de los bocetos y la técnica, tinta y aguadas; los temas son paisajes valencianos y algunos de tema arqueológico que hizó sobre los Baños de la Reina próximos a Calpe. La elaboración es posterior a las excursiones, siendo realizados seguramente en Madrid, teniendo como único recuerdo de los lugares los bocetos que realizó en el viaje. Los dibujos no sufrieron apenas modificaciones al ser grabados, salvo en algunos de ellos donde aparece una figura humana incorporada al paisaje y formando parte de él.

No se puede dejar de resaltar el importante «Mapa del. Reino de Valencia por D. Antonio Josef Cavanilles. Madrid, 1795», donde figura al pie: "Se concluyó este mapa en 3 de Diciembre de 1794» y firmado A. J. Cavanilles. Lo rea-

17 Vease el Catálogo General de la Calcografía Nacional (1987), Madrid, p. 157-159. 
lizó igualmente a tinta y lápiz, sobre papel verjurado; por sus grandes dimensiones -79 × $47 \mathrm{~cm}$ - debía ser insertado plegado al final de la publicación. Está orientado, tiene representación orográfica y reseña multitud de núcleos de población. Hizo unas listas externas con las poblaciones y los accidentes geográficos más relevantes ${ }^{18}$.

La última fase de la creación de su trabajo es la obra impresa, compuesta por dos volúmenes. En esta caja llegaron dos de ellos, encuadernados en pasta española, en folio mayor, con guardas pintadas al agua y cortes dorados, que tal vez pertenecieran al propio autor, aunque no hay vestigios de ello. El primer volumen fue publicado en Madrid, en la Imprenta Real, en 1795. El segundo está publicado en el mismo lugar, siendo regente D. Pedro Julián Pereyra, impresor de Cámara de S. M., y en 1797.

Contiene además esta caja del Reino de Valencia una lista de 331 muestras de piedras recogidas por Cavanilles, donde describe su aspecto, color, dureza y el lugar donde las recogió. Estas muestras las mandó pulir al maestro cantero, Florentino Cubillas, que elaboró otra relación con los resultados del proceso de pulimentación. La factura de su trabajo, fechada a 15 de agosto de 1792 , ascendía a 294 reales.

En esta caja se encontraban también los dibujos originales para los Icones et descriptiones plantarum..., obra comenzada por Real Orden de 14 de septiembre de 1790 y la más extensa por estar compuesta por seis volúmenes. Los dibujos, en número de 600, están encuadernados —también en 6 volúmenes como la obra impresa- en pasta española con orla dorada, lomo liso con tejuelos, las guardas pintadas al agua, los cortes pintados y con cintas indicadoras de seda rosa. Son de tamaño folio y papel verjurado, su técnica es también lápiz y aguadas de tinta dentro de la gama de los grises. Todos los dibujos están firmados por A. J. Cavanilles con la abreviatura del. [delineavit] a continuación del nombre en el margen inferior izquierdo, dejando el derecho libre para la firma del grabador. Contienen información de dónde fue dibujada cada planta viva, los diez primeras en París y el resto en España, principalmente en el Jardín Botánico de Madrid. Anota la fecha y en algunas ocasiones observaciones sobre la planta, su procedencia, período de floración, habitat, etc... Aunque en origen todos debieron de tener estos datos, al ser encuadernados, los dibujos fueron guillotinados y algunos perdieron esta información. La obra fue publicada por cuadernos de diez estampas y cada diez de éstos formaron un volumen de 100 estampas. Las láminas grabadas, de las que se conservan 172 en la Calcografía Nacional, son obra de F.N. Sellier, M. Gamborino, T. y V. López Enguidanos, J. Fonseca y A. Blanco.

${ }^{18}$ La restauración de los dibujos del Reinó de Valencia se ha llevado a cabo con una subvención de la Institució Valenciana d'Estudis i Investigació (I.V.E.I), por la restauradora Gloria Pérez de Rada Cavanilles.

Asclepio-Vol. XLVII-1-1995 


\section{MARIA PILAR DE SAN PIO ALADREN Y PALOMA COLLAR DEL CASTILLO}

8. La caja octava lleva por título POLÉMICA SOBRE EL CULTIVO DEL ARROZ. A pesar de que su extensión es muy pequeña, el tema que trata es muy polémico y enfrenta intereses muy encontrados. Por un lado, presenta el beneficio económico que producía el cultivo del arroz y, por otro, las duras condiciones de vida que este cultivo imponía a los trabajadores, así como la insalubridad de las poblaciones que rodeaban a los lugares de cultivo. Los temas de estudio tratados en esta serie son muy interesantes y coinciden con el interés actual por preservar las zonas húmedas como lugares donde la vida animal y vegetal se multiplica muy rápida y abundantemente.

Consta de diez carpetas, en su mayoría cartas que tratan sobre el cultivo del arroz en tierras valencianas. Sigue una relación añadiendo su número y las fechas en que fueron remitidas.

1. S.f.-Nueve notas en relación al cultivo de arroces.

2. 1783-1803.-Cinco cartas de Vicente Blasco.

3. S. f.- "Cartas de un cura a un amigo", en defensa del cultivo del arroz en la Rivera de Valencia.

4. 1803.-Una carta de Vicente Soriano.

5. S. f.-Representación hecha al Rey por Juan Bautista Madamany, vecino de Alcudia de Carlet, y Pedro Juan Franco, vecino de la Villa de Villanueva de Castellón, en nombre de los arroceros de esta villa, pidiendo que se les conceda licencia y facultad para la cría de arroces.

6. 1796-1797.-Tres cartas de Pascual Caro.

7. 1798.-Una carta de Juan Antonio Pérez Clemente.

8. 1797-1798.-Dos cartas de Vicente Ignacio Franco a Cavanilles y al Sr. Muñoz y un ejemplar impreso en Valencia en 1797 de la «Contestación a las Observaciones sobre la necesidad de la cría de arroces en las Riveras Xúcar, Reino de Valencia....» de Vicente Ignacio Franco.

9. 1797-1798.-Cinco cartas de Francisco Llansol, vecino de Alcira y un mapa topográfico de la Rivera del Xúcar, tamaño folio, en papel verjurado y dibujado a tinta sepia. Sin firma.

9. La caja novena lleva por título OBRAS VARIAS, INÉDITAS E IMPRESAS y contiene siete obras, de algunas de las cuales hay varios ejemplares. ${ }^{19}$

1. Manuscrito autógrafo de Cavanilles en cuya portada aparece la siguiente inscripción: «Empezé el estudio de la Botanica en el Otoño de 1780 y las descripciones contenidas en este tomo en 1782 que continué en los dos siguientes de 83 y 84 . Hacíalas como aprendiz, sin el conocimiento que luego

\footnotetext{
19 Las autoras agradecen a Gloria Pérez de Rada Cavanilles, restauradora de obras gráficas del Real Jardín Botánico, su ayuda en la descripción de las obras encuadernadas.
} 
adquiría tratando con los Sres. de Jussieu, Thouin, Lamarck, Desfontaines, Beauprés, etc., viendo los Jardines de Trianon y M. Monnier en Versalles; de Bellevue, Real de París, y los de Cels y Saint Germain en la misma capital; otros famosos de Sèvres; muchos de Bruxellas, y las plantas espontáneas de los sitios por donde iba viajando. Revolví Herbarios y autores; rectifiqué mis ideas y notando yerros y faltas en autores empezé a preparar mis obras publicando la primera en 1785. Antonio Josef Cavanilles.) Contiene 197 hojas, en cuarto mayor, encuadernado en badana verde con cintas, lomo liso con hierros y tejuelo, cortes pintados y guardas lisas. Escrito en tinta sepia. También le acompañan dos apéndices independientes con listas de plantas, una de ellas de su herbario entre 1781 y 1783.

2. Copia manuscrita del Hortus Regius Matritensis. Las descripciones están realizadas por varias letras diferentes. Al final, aparece una certificación de Francisco Antonio Zea, fechada en Madrid a 14 de noviembre de 1804, diciendo que es una copia del original que le entregó, escrito de su mano Antonio José Cavanilles salvo las descripciones de la «atriplex verticillata», escrita por Mariano de Lagasca, y la «Mimosa Leptophylla», con letra de Emeterio Rodríguez, y que él mismo certifica esta copia rubricando cada hoja. Contiene una lista de los dibujos que ha realizado José Guío, dibujante del Real Jardín Botánico. Volumen en cuarto, encuadernado en cabra verde, tapas gofradas con orla dorada, lomo liso con hierros, cantos dorados, guardas serigrafiadas.

3. Un ejemplar de la obra Descripción de las plantas que D. Antonio Josef Cavanilles demostró en las Lecciones Públicas del año 1801, precedida de los Principios Elementales de la Botánica. Madrid: en la Imprenta Real, año 1802. En cuarto, encuadernación en pasta española, lomo con cinco nervios, tejuelo y hierros, cortes salpicados, guardas pintadas al agua y cinta señaladora de seda. En una de las últimas páginas hay una pequeña anotación de Cavanilles sobre la Randia y la Gardenia.

4. Tres ejemplares impresos de las Observations de M. L'Abbé Cavanilles sur l'article Espagne, de la Nouvelle Encyclopédie. «À Paris: Chez Alex. Jombert jeune, rue Dauphine, 1784. Avec approbation, et privilege du Roi.» El primero es la obra completa, en cuarto, encuadernada en pasta española, orla dorada, lomo liso con hierros y tejuelos, guardas pintadas al agua y cantos dorados. El segundo está encuadernado en rústica y todavía sin abrir. El tercero, también impreso, lleva insertadas unas hojas en blanco, donde el autor realizó alguna corrección manuscrita para la imprenta.

5. Son dos ejemplares de la Colección de papeles sobre controversias botánicas de D. Antonio Joseph Cavanilles, con algunas notas del mismo a los escri- 
tos de sus antagonistas. Madrid: En la Imprenta Real, Año de 1796. Los dos libros son muy semejantes, en octava, encuadernados en pasta española, con lomo liso con hierros y tejuelo, cantos dorados, guardas pintadas al agua y cinta señaladora de seda. Recogen las polémicas mantenidas entre otros con Hipólito Ruiz, botánico de la Expedición de Perú y Chile (1777-1788). Incluyen igualmente las diferencias con los cultivadores de arroz en la región valenciana, titulando a esta segunda: «Suplemento a las observaciones sobre el cultivo del arroz en el Reyno de Valencia, y su influencia en la salud pública, en respuesta a la contestación de D. Vicente Ignacio Franco. por D. Antonio Joseph Cavanilles, Académico de número de la Real Academia de Medicina de Madrid.» Madrid: en la Imprenta Real, año de 1798.

6. Manuscrito encabezado "Carolia Linné systema plantarum editio novissima an. 1779», de 71 hojas en dieciseisavo, encuadernado en pasta española, orla dorada, lomo liso, y cantos, contracantos y cortes dorados, las guardas al agua y cinta separadora de seda. Cavanilles escribió, en latín, una lista de 1334 plantas con una descripción muy somera.

7. Manuscrito autógrafo en cuya portada aparece el título: «Apuntamientos lógicos. o Compendio del Arte logico-critica para el uso. del Excmo. Sor. Conde de Saldaña y de su hermano El Sor. Dn. Manl de Toledo y Salm Salm. Año 1.780». Tiene 66 hojas escritas, en cuarto. La encuadernación es especialmente bonita en cabra roja, orla dorada, lomo liso cuajado y con tejuelo verde, cantos, contracantos y cortes dorados, guardas pintadas al agua y caligrafía muy esmerada en tinta sepia. En la pasta del libro está grabada la palabra INFANTADO. En el prólogo, firmado por él, justifica haber escrito esta obra para la educación de sus alumnos. La divide en dieciocho capítulos sobre temas de Lógica, pero sin adentrarse en el trabajo histórico de su evolución. Al final del volumen comenta su satisfacción porque cree que su libro obedece fielmente al plan marcado con anterioridad para instruir a sus alumnos sobre la formación y el perfeccionamiento del espíritu humano.

10.-La caja décima tiene por título OBRAS-DISERTACIONES BOTÁNICAS, $1{ }^{\text {er }}$ EJEMPLAR. Texto. Consta de once carpetas, cada una con uno de los once cuadernillos impresos que forman la obra Monadelphiae classis dissertationes decem. Matriti: ex typographia regia, 1790. Fue su primera publicación botánica y cada cuadernillo tiene una fecha diferente. Su relación es la siguiente:

1. Monadelphiae classis dissertationes decem. Madrid. 1790. Contiene un prefacio y una introducción al genero Monadelphiae.

2. Dissertatio botanica de Sida. París, 1785. 


\section{EL ARCHIVO DE A.J. CAVANILLES EN EL REAL JARDIN BOTANICO}

3. Secunda dissertatio botanica. De Malva, Serra, Malope, Lavatera, Alcea, Althaea et Malachra. París, 1786.

4. Tertia dissertatio botanica. De Ruizia, Assonia, Dombeya, Pentapete, Malvavisco, Pavonia, Hibisco, Laguna, Cienfuegosia, Quararibea, Pachira, Hugonia et Monsonia. París, 1787.

5. Quarta dissertatio botanica. De Geranio, 128 species complectens, 49 tabulis incisas. París, 1787.

6. Quinta dissertatio botanica. De Sterculia, Kleinhovia, Ayenia, Buttneria, Bombace, Adansonia, Crinodendro, Aytonia, Malachodendro, Stewartia et Napaea. París, 1788.

7. Sexta dissertatio botanica. De Camellia, Gordonia, Morisona, Gossypio, Waltheria, Melochia, Mahernia, Hermannia, Urena, Halesia, Styrace, Galxia, Ferraria, et Sisyrinchio. París, 1788.

8. Septima dissertatio botanica. Quatuordecim genera monadelpha continens, 24 tabulis accurate delineata. París, 1789.

9. Octava dissertatio botanica. Erythroxylon et Malpighiam complectens, 18 tabulis ornata. París, 1789.

10. Nona dissertatio botanica. De Banisteria, Triopteride, Tetrapteride, Molina et Flabellaria, 22 tabulis ornata. Madrid, 1790.

11. Decima dissertatio botanica. De Passiflora, 39 tabulis ornata. Madrid, 1790.

11. La caja número once se titula OBRAS-DISERTACIONES BOTÁNICAS, 1er EJEMPLAR. Láminas. Es la parte gráfica de la obra anterior. La compone un conjunto de 296 estampas grabadas, que pueden ser primeras pruebas. Todas hechas por el grabador F.N. Sellier a partir de los dibujos originales que Cavanilles realizó y que, como ya se ha mencionado, se encontraban en el Real Jardín Botánico antes de la llegada del "Archivo Cavanilles». Con estas estampas se completa la documentación de esta obra en el archivo del Jardín. En la Calcografía Nacional se guardan ciento cuatro planchas de cobre de las que sirvieron para hacer las estampas.

12.-La caja número doce está designada como: PAPELES DE DON JOSÉ THOMÁS CAVANILLES. Consiste sólo en un volumen encuadernado en becerro marrón, tapas gofradas con orla dorada, lomo liso con hierros, cantos dorados, y guardas lisas en papel verjurado. En el lomo figura el título: «Destinos y Comisiones que sirvió el ilustrísimo Sr. D. José [Thomas] Cavanilles [y Mas]", y está compuesto por títulos y nombramientos originales. Resalta entre ellos un certificado de su título de abogado, firmado el 9 de julio de 1792 en Valencia, y el nombramiento de Alcalde Mayor de la Audiencia del Principado de Asturias, fechado en Aranjuez el 4 de mayo de 1796 y firmado - Yo el Rey. También existe un certificado oficial, firmado por el Presidente de la Junta de 
Protección del Real Museo de Ciencias Naturales de Madrid, en el que se le nombra discípulo de la Cátedra de Agricultura, en Madrid el 17 de noviembre de 1817, siendo su profesor Antonio Sandalio de Arias. Al final del libro encuadernado se encuentra un dibujo de su mausoleo y la inscripción de la lápida. Contiene también un total de diecisiete documentos independientes, muchos de ellos son cuentas de gastos producidos por diferentes motivos, viajes, alquileres, traslados, etc...

A pesar de que los documentos reseñados en el inventario publicado del "Archivo Cavanilles» terminan aquí, venían en el legado cuatro pequeñas publicaciones sobre Cavanilles que la familia también había guardado:

a) «Bicentenario de Cavanilles» por J. G. García. Separata del Anuário da Sociedade Broteriana -ano XII-Coimbra 1946.

b) "Três cartas inéditas de Brotero a Cavanilles" por Américo Pires de Lima. Separata del Anuário da Sociedade Broteriana -ano XII- Coimbra 1946.

c) Elogio histórico de don Antonio José Cavanilles, de José Pizcueta. 2. ${ }^{\mathrm{a}}$ ed. Madrid, 1930. Contiene un ex-libris del XVII duque del Infantado.

d) Diálogos por Antonio Cavanilles [Centi]. Madrid: imprenta de J. Martín Alegría, 1857. Este ejemplar es una reimpresión hecha en la Imprenta de Blass en Madrid, en 1932. Es una recopilación de diálogos, cartas y discursos académicos.

$$
\text { 米棌 }
$$

La relación de documentos que se ha presentado permite concluir que el «Archivo Cavanilles» puede prestar una enorme ayuda para conocer y reconstruir el pasado de la Ciencia Botánica en la España de fines del s. XVIII y principios del s. XIX. Su puesta a disposición de investigadores y estudiosos, depositándolo en un archivo público, es un gesto admirable que merece el reconocimiento general. Pero este acto de generosidad será realmente recompensado a medida que produzca los frutos deseados: el estudio en mayor profundidad de Antonio José Cavanilles y de la obra que realizó en favor del desarrollo de la Ciencia. 